\title{
MENTALIDADE SOCIAL E RESISTÊNCIA: ANÁLISE SOCIAL E POLÍTICA DO GRUPO ELDORADO DOS CARAJÁS - MS
}

\author{
SOCIAL MENTALITY AND RESISTENCE: ANALYSIS SOCIAL AND \\ POLITICAL ANALYSIS OF THE ELDORADO DOS CARAJÁS GROUP-MS
}

Silvana Piva ${ }^{1}$

http://lattes.cnpq.br/6722531236526851

\section{Fabricio Antônio Deffacci²}

http://lattes.cnpq.br/2950092026989100

Recebido em 26/08/2018

Aceito em 25/11/2019

Resumo: O objetivo desta pesquisa é compreender os principais aspectos da mentalidade social e política do Núcleo de Resistência Eldorado dos Carajás, tendo em vista que a principal marca de organização do Grupo é o sentimento de pertença a partir da luta encampada pela conquista e uso da terra. O grupo em questão pertence ao maior assentamento em extensão territorial da América Latina - Assentamento Itamarati -, o qual tem 50 mil hectares de terra, estando localizado no Município de Ponta Porã/MS. O grupo enfocado apresenta como peculiaridade a organização coletiva por parte de seus membros, tendo em vista ir além dos princípios capitalistas no campo da produção e da organização socioeconômica. Para desdobrar tal objetivo, do ponto de vista metodológico, a pesquisa combinou dois momentos, isto é, a interação entre teoria e empiria. Neste processo ininterrupto entre a crença no coletivo e o perigo iminente do individualismo podemos considerar que emerge no N17 uma forma híbrida de organização social entre ideologia e utopia marcada pelas fissuras no sistema.

Palavras Chaves: Assentamento Itamarati; Organização Socioeconômica; Sentimento de Pertença.

\begin{abstract}
The objective of this research is to understand the main aspects of the social and political mentality of the in the Eldorado resistence nucleus. The group in question belongs to the largest settlement in territorial extension of Latin America - Settlements Itamarati -, which has 50000 hectares of land, being located in the municipality of Ponta Porã/MS. The focus group presentes as a peculiarity the collective organization on the part of its members, in order to go beyond the capitalist principales in the field of production and socioeconomic organization. To unfold this objective, from a methodological point of view, the research combined two moments, that is, the interaction between theory and empirically.In this uninterrupted process between the belief in the collective and the imminent danger of individualism we can consider that emerges in the N17 a bybrid form of social organization between ideology and utopia marked by the cracks in the system.
\end{abstract}

Key words: Itamarati Settlement; Socio-economic Organization; Feeling of Belonging.

1 Mestre em Desenvolvimento Regional e Sistemas Produtivos pela Universidade Estadual de Mato Grosso do Sul. Brasil (2018). E-mail: silvanapivaa@gmail.com.

2 Doutor em Ciências Sociais pela Universidade Estadual Paulista Júlio de Mesquita Filho, Brasil (2012). Docente da Universidade Estadual de Mato Grosso do Sul. E-mail: fabricio.deffacci@gmail.com 


\section{O NÚCLEO DE RESISTÊNCIA ELDORADO DOS CARAJÁS (N17): ELEMENTOS INTRODUTÓRIOS}

O Mato Grosso do Sul dispõe de expressiva quantidade territorial, contudo, nos períodos de 1996 e 2006, é perceptível um aumento nas chamadas pequenas propriedades rurais. De acordo com Bittar (2009) acerca da formação histórica do estado, esse aumento significativo é decorrente do crescimento do número de reivindicações sociais transformando grandes propriedades de terra do estado em assentamentos rurais.

O estado de Mato Grosso do Sul possui uma área de 716.105 hectares de terra, para 204 projetos de assentamentos rurais, residindo um total de 27.841 famílias assentadas nessas localidades. Dos 78 municípios do estado 54 deles apresentam assentamentos (INCRA, 2016). Só no município de Ponta Porã/MS são sete. Logo, é notável que a região dispõe de uma extensão territorial marcada pelas possibilidades abertas para a reforma agrária, totalizando mais de 65 mil hectares de terra para assentamentos rurais.

A região de Ponta Porã-MS abarca o maior assentamento da América latina em extensão territorial: o Assentamento Itamarati. Este é composto por 50 mil hectares de terra, estando localizado na rodovia MS-164, à 280 quilômetros da capital do estado Campo Grande/MS, a 54 quilômetros do município de Ponta Porã e 25 quilômetros da fronteira com o Paraguai.

Antes da distribuição da terra para a concretização do assentamento, o local era uma fazenda denominada Fazenda Itamarati, de prestígio internacional por sua característica de maior produtora de soja da região. O proprietário da fazenda, Olacyr de Moraes, era conhecido como "Rei da Soja". No entanto, o declínio da Fazenda Itamarati ocorreu em 2000, devido à dívida advinda pela aquisição de crédito rural, a qual o proprietário se viu impossibilitado de honrar com seus compromissos e teve que entregar sua propriedade em forma de pagamento. Terra (2009) explica o modo como o governo federal adquiriu tais terras: "O governo federal adquiriu junto ao Banco Itaú 25.100 ha das terras que haviam pertencido à Fazenda Itamarati, os quais foram repassados em maio de 2001 para o Instituto de Colonização e Reforma Agrária (INCRA), que deu início à implantação do Assentamento Itamarati..." Neste espaço, "foram assentadas 1.143 famílias e, posteriormente em maio de 2004, o governo federal viria adquirir o restante da fazenda (24.900 ha) junto ao proprietário para a Implantação do assentamento Itamarati II.” (TERRA, 2009, p.18).

Devido a esse motivo o assentamento tem sua ramificação em Itamarati I e Itamarati II, pois, as terras adquiridas para a reforma agrária foram divididas em duas etapas. Vivem atualmente no local 15.867 habitantes de acordo com dados do Instituto Nacional de Colonização Agrícola - INCRA. A população desenvolve atividades nas modalidades agrícolas, pecuária de corte, pecuária leiteira, entre outros. Há um núcleo urbano onde funciona a área comercial do local.

O assentamento possui infraestrutura básica de energia elétrica rural, abastecimento de água e meios de comunicação. A estrutura educacional é composta de três escolas, de responsabilidade do governo estadual e uma creche que funciona em período integral sob a incumbência do governo municipal, para atender a comunidade local. As estradas internas do assentamento possuem cerca de $680 \mathrm{~km}$ de vias não pavimentadas. Na área de saúde, o assentamento dispõe de três postos de saúde que contam com uma ambulância para deslocamento de paciente à cidade de Ponta Porã.

A área do assentamento Itamarati, denominada como Itamarati I, adquirida em 2000, está 
dividida em quatro subáreas, de acordo com os movimentos sociais existentes no local. $\mathrm{O}$ Plano de Desenvolvimento do Assentamento Itamarati - PLA (2002) possuía como objetivo incipiente assentar na primeira etapa da divisão do assentamento um número de 1.143 trabalhadores e implantar projetos cooperativos buscando um crescimento local. O objetivo proposto pelo PLA foi lançado, e dessa forma a produção e organização dos grupos foi feita de acordo com os grupos que se instalaram no Assentamento. A proposta inicial sofreu alterações com o passar do tempo e se reestrutura a medida das necessidades das famílias e dos grupos. O assentamento Itamarati II tem cerca de 1.760 famílias.

A organização da distribuição da terra para as famílias ocorreu de maneira que todos os assentados pudessem ser beneficiados com a infraestrutura que o INCRA adquiriu com a aquisição da fazenda, totalizando 19 pivôs de irrigação.

Para beneficiar a todos dividiu-se a terra em área de sequeiro que correspondia uma parcela de 04 hectares para produção individual das famílias possibilitando-as de plantarem o que desejassem e a quantia de 12 hectares ficou para a área do pivô que é a chamada área do coletivo. Porém, alguns grupos fizeram a divisão igualitária de 06 hectares para a produção individual e o restante para a área coletiva (do pivô).

Neste contexto, o grupo Núcleo de Resistência Eldorado dos Carajás, por sua peculiaridade de organização é o objeto de estudo dessa pesquisa. De forma consensual os membros que constituem o grupo decidiram manter o formato de uma única terra, ou seja, não houve divisão individual, manifestando-se um modelo de organização coletiva distinto dos demais.

A área do assentamento, de acordo com o Plano de Desenvolvimento do Assentamento Itamarati (2002, p.14) é dividida em 04 grandes grupos sociais. Ainda de acordo com o Plano, o Movimento dos Trabalhadores Rurais Sem Terra (MST) está representado por 320 famílias; a Central Única dos Trabalhadores (CUT) possui 280 famílias; a Federação dos Trabalhadores na Agricultura (FETAGRI) tem 395 famílias e a Associação dos Moradores e Funcionários da Fazenda Itamarati (AMFFI) tem 150 famílias assentadas. Cada grande grupo subdivide-se em grupos menores, com exceção da AMFFI, que compôs um grupo único.

O Núcleo de Resistência Eldorado dos Carajás (N17) está inserido no Grupo Movimento dos Trabalhadores Rurais Sem Terra (MST). Sendo conhecido e autodenominado tanto pelos membros como pela comunidade de Grupo 17 e/ou Grupo coletivo. Até atingir o número de famílias necessárias para a formação do grupo foram feitas muitas visitas e reuniões mostrando a importância de cada membro para consolidação do N17. De acordo com os relatos dos entrevistados a partir daí inicia a história do Núcleo de Resistência Eldorado do Carajás, cujo nome deriva da homenagem ao fato ocorrido em 17 de abril de 1996, no município de Eldorado dos Carajás, no sul do Pará. Segundo a entrevistada I "Escolhemos esse nome porque somos o grupo dezessete com dezenove famílias e o massacre ocorreu no dia 17 e se foram 19 companheiros, então tínhamos muita semelhança e resistência, foi por conta da resistência e compromisso com a luta que se deu o nome do grupo."

O N17 possui um Estatuto Social denominado Sociedade dos Agricultores Cooperados do Núcleo de Resistência Eldorado do Carajás (SOCIAEC) que os regem, o qual foi elaborado em concomitância com todos os seus membros. O Estatuto tem como prerrogativa dar sustentação ao propósito estabelecido pelo grupo, objetivando congregar os agricultores de sua área de ação e desenvolver a produção agropecuária e prestação de quaisquer serviços que possam contribuir para o fomento, racionalização de recursos financeiros e naturais, desenvolvimento e bem-estar dos associados bem como a defesa das atividades econômicas, 
sociais, culturais e políticas (ESTATUTO SOCIAL, 2017).

Hoje o grupo possui 16 famílias que estão concentradas estritamente no Itamarati I situado no Projeto de Assentamento Conquista na Fronteira (MST) e com localização a $20 \mathrm{~km}$ da área urbana do assentamento e a 74 km do município de Ponta Porã-MS.

Diante deste cenário histórico, o objetivo deste trabalho é compreender os principais aspectos da mentalidade social e política do N17, tendo em vista que a principal marca de organização do Grupo que é o sentimento de pertença a partir da luta encampada pela conquista e uso da terra. Com base nesta luta emerge também o sentimento de resistência ao "sistema vigente e opressor", mantido sob a forma de mentalidade capitalista, a qual se apresenta para o Grupo enquanto excludente e demasiadamente competitiva. Neste viés, destaca-se o individualismo que precisa ser combatido dentro do Grupo por meio de ideais coletivos e solidários. Em se tratando de tais ideais, a análise será apoiada nos referenciais teóricos do sociólogo húngaro Karl Mannheim, procurando compreender a mentalidade social por meio das construções ideacionais que refletem o meio no qual os indivíduos estão inseridos. Tais construções podem se manifestar de dois modos distintos. Trata-se de uma defesa acerca da realidade presente, a qual converge para a construção de mentalidades ideológicas ou, de modo contrário, a busca por superação da realidade, o que caracteriza a elaboração de um pensamento socialmente condicionado e com traços desiderativos que implicam na produção de utopias como indicação de uma possível realidade futura. Entre ambos os casos de manifestação da mentalidade social o que vamos encontrar é a disputa no campo político, colocando frente a frente o ideológico e o utópico em busca de uma nova síntese social.

O percurso metodológico para contemplar o objetivo da pesquisa está construído entre a teoria e a empiria, possibilitando o diálogo constante entre os conceitos e os dados obtidos. A análise será apoiada nos referenciais do sociólogo húngaro Karl Mannheim que procura compreender a mentalidade social por meio das construções ideacionais que refletem o meio no qual os indivíduos estão inseridos. A mentalidade social do N17 corresponderá ao sentido qualitativo desta pesquisa. Para Dencker (1998) a metodologia do tipo qualitativo está relacionada na observação dos fenômenos sociais de maneira intensa. Foi utilizada também a metodologia da observação participante que pode ser conceituado por May (2001, p.177) como o processo "no qual um investigador estabelece um relacionamento multilateral e de prazo relativamente longo com uma associação humana na sua situação natural com o propósito de desenvolver um entendimento científico daquele grupo". Em meio ao convívio direto com o N17 foi obtido dados por meio de entrevistas abertas. Segundo Dencker (1998, p.104) a entrevista "pode ser a principal técnica empregada ou estar inclusa no processo de observação.” Em geral, nas pesquisas qualitativas, as entrevistas são pouco estruturadas, assemelhando-se a uma conversa." Deste modo o autor Haguatte (1997) explica que a entrevista em profundidade possui validade à medida que o pesquisador conheça pouco a realidade do contexto estudado, pois dessa forma não terá de maneira direta tanta interferência com a opinião do pesquisador na investigação. Flick (2009) ressalta também que as entrevistas não estruturadas conferem mais liberdade à conversação entre entrevistador e entrevistado conseguem colher desta maneira informações da realidade, que com a entrevista estruturada não conseguiria, pois, tira do entrevistado a liberdade de expor sua realidade. Além dessas formas de abordagens utilizamos documentos referentes ao grupo: estatuto do grupo e atas de assembleias. Assim tornou-se possível colher de forma concreta os dados inerentes ao levantamento histórico e de organização do N17. Esse mecanismo é um recurso excelente

PRACS: Revista Eletrônica de Humanidades do Curso de Ciências Sociais da UNIFAP https://periodicos.unifap.br/index.php/pracs ISSN 1984-4352 Macapá, v. 12, n. 2, p. 119-133, jul./dez. 2019 
para uma adição mais intensa das representações e práticas vividas pelo grupo estudado, pois fornece ao pesquisador uma análise mais abrangente e específica do campo.

\section{A MENTALIDADE SOCIAL EM PERSPECTIVA TEÓRICA}

A base teórica para se conceber a mentalidade social em sua dinâmica ininterrupta é, para Mannheim, a via de compreensão de dois tipos de mentalidade que se relacionam constantemente na formação e desintegração da ordem social. Trata-se da ideologia e da utopia que estão relacionadas às motivações coletivas muitas vezes geradas inconscientemente pelos indivíduos, atuando e determinando principalmente o agir e o pensar. Ideologia e utopia são modos de agrupamentos de ideias que perpassam os indivíduos. Nesse sentido, a análise de uma ideia individual precisa passar pela observação de sua origem social que identifica o modo como a ideologia se apresenta a partir de fatores vivenciais voltados para a "conservação" e a utopia pelo fator "mudança". No entanto, ambas distorcem a realidade, mesmo que estando em sintonia direta com a realidade do grupo e de suas experiências existencialmente construídas (MANNHEIM 1972).

Deste modo refere-se à ideologia como o conjunto de ideias que objetivam manter a ordem existente e utopia como as ideias que dão fundamento as ações pela busca de transformação desta ordem existente. Os traços que significam a parte utópica do N17 permeiam a criação do grupo, as ideias que os jovens militantes do MST pensaram em conjunto, estudaram e amadureceram, isto é, a ideia de formação de um grupo coletivo contrastando com a ordem existente.

Para Mannheim (1976) quando o indivíduo pensa, esse pensamento não é puramente individual pois é antes um pensamento socialmente condicionado, isto é, a produção de ideias está diretamente vinculada à necessidade de produção dos meios materiais de sobrevivência, bem como a produção das estratégias para a luta política. Logo, o indivíduo utiliza definições e conceitos que pertencem ao grupo e são por ele utilizadas e repensadas em conformidade com as necessidades presentes. Trata-se de um conjunto de traços, significações e valores sociais aberto, dinâmico e com possibilidade de ressignificação. No N17 vamos encontrar um conjunto de experiências provenientes do Sul do País que se apresentam como motivador da luta contra a ordem social ideologicamente firmada e, ao mesmo tempo, abertura para a dinâmica inerente à realidade social em seu estágio desiderativo que visa à construção de utopias. Assim, é por meio de definições, conceitos e experiências que os jovens militantes do MST construíram e afirmaram o projeto do grupo coletivo: o N17.

O pensamento só apresenta traços pessoais aparentemente quando situa elementos históricos e sociais de seu meio, de modo que sempre carrega as características do meio em que está inserido. Mannheim (1972, p.53) denomina esse estágio do pensamento de "um complexo de conduta significativa, que pode ser compreendida em termos de sua estrutura motivacional ou de seu contexto de experiência". Para compreender os pensamentos históricos e sociais é preciso fazer uma análise da situação. Mannheim (1972) refere-se a essa situação como o modo de pensamento em todas as formas de experiência que vai além e acima do nível do lugar-comum ocupado pelos indivíduos. É a produção de um estilo de pensamento socialmente compartilhado que atua como ponta de lança para a abertura de novas formas de se conceber a realidade e, portanto, para o estabelecimento da luta política em derivação das tensões socialmente produzidas nas mentalidades. 
Contudo, a noção de ideologia para Mannheim perpassa as descobertas emergentes do sistema e, principalmente, os conflitos políticos, de modo que os grupos dominantes estão intensamente ligados por interesses, e que de alguma maneira acabam por ocultar suas ações destinadas para a dominação. Na concepção de ideologia está contida a concepção de que, em certos cenários, o coletivo inconscientemente obscurece as condições reais da sociedade e deste modo acaba tanto para si como para os demais estabilizando a situação.

Em outra direção, para o autor o pensar utópico perpassa alguns grupos menos favorecidos que estão interessados em mudanças e principalmente na ruptura e transformação de uma dada condição imposta pela sociedade, situando-se apenas nos elementos que negam essas mudanças. No entanto, acabam por negar a situação existente, estando preocupados em mudar a situação existente e não o que antes existia. O pensamento utópico não será um diagnóstico da situação, mas será apenas uma orientação para a ação que poderá ser ou não tomada. Assim, na mentalidade utópica e no inconsciente coletivo o desejo pela ação é guiado pela representação oculta de alguns aspectos da realidade.

Diante disso, a utopia para Mannheim não apenas se desprende da ideologia, mais também do real, daquilo que está posto na ordem existente. A utopia passa a ser algo para ser vivenciado no agora deste modo, "um estado de espírito é utópico quando está em incongruência com o estado de realidade dentro do qual ocorre" (Mannheim, 1976, p. 216). Portanto, o conjunto de ideias de um determinado grupo social não precisa necessariamente ultrapassar a ordem existente (o sistema) para ser considerada utópica, mas é fundamental que sua orientação pela ruptura das amarras com o existente seja central.

Podemos dizer que em todos os períodos da história certos ideais ultrapassaram a ordem existente, mas nem por isso transformaram-se em função das utopias, pois antes eram consideradas ideologias adequadas para a existência, de modo que não ofereciam possibilidades de rupturas. Nessa concepção, para uma parcela dos indivíduos os acontecimentos correspondiam a ordem existente, já para a outra parcela (a minoria) incorporava imagens desiderativas das condutas efervescentes da época em confronto com as ideologias, oportunizando o surgimento de ideais utópicos.

O papel utópico desempenha ideias que só podem ser desenhadas quando adquire um "estado de espírito utópico" no que se refere a ultrapassar a ordem. Logo, precisa modificar e transformar os elementos, incorporando nos grupos sociais a capacidade de revolucionar a ordem vigente. Com isso, a compreensão da mentalidade utópica baseia-se na revolução, na quebra e, na ruptura da ordem. Por outro lado, a ideologia está sempre entrelaçada com o existente mediante os padrões da ordem (MANNHEIM, 1976).

Diante das mentalidades constituídas, o ponto de partida é ideológico e, nesse sentido, Mannheim identifica duas formas básicas de ideologia a particular ou parcial (que pode ser parcial ou individual) e a ideologia total (chamada também de coletiva ou de grupo). Deste modo, esses dois momentos da ideologia, tanto o parcial quanto o total, são identificados como formas tradicionais de concepção da realidade social. A consolidação das formas ideológicas implica em uma tendência de ocultar o real significado da conduta ao invés de revelálo.

Mannheim considera a atitude de afrontar os pensamentos e concepções de mundo estabelecidas mediante a percepção dos processos históricos, o que não significa que a visão do outro possa ser simplesmente considerada mentira. E, deste mesmo modo de pensar, para outros indivíduos, essa visão do outro deve ser considerada como ideologia particular. $\mathrm{Na}$ dis-

PRACS: Revista Eletrônica de Humanidades do Curso de Ciências Sociais da UNIFAP https://periodicos.unifap.br/index.php/pracs ISSN 1984-4352 Macapá, v. 12, n. 2, p. 119-133, jul./dez. 2019 
puta de pensamentos, uns contra e outros, é relativo mensurar quem ou o que está correto. De outro modo, cada indivíduo passa a pensar e agir conforme acredita ser melhor para seu meio e em conformidade com o lugar ocupado na sociedade. Ademais, para que a ideologia particular possa se expressar na ideologia total, necessita da visão unitária de mundo e que essa visão se compreenda em valores comuns. Caso contrário, uma ideologia particular que não se encaixa na ideologia total pode carregar em si elementos para a construção de um pensamento desiderativo. É importante frisar que o conhecimento determinado pelos elementos sociais e históricos transforma o conhecimento em conhecimento relativo prevendo uma tomada de consciência de uma verdade total em que o grupo seja capaz de operacionalizar suas ações (MANNHEIM 1972).

Diante de tamanha questão teórica e conceitual, é perceptível que os movimentos sociais que afrontaram os aspectos existentes para romper o que estava dito tiveram que vencê-los ou então adaptar-se. Em meio a essa disputa, torna-se necessário o embate político no âmbito das mentalidades para demonstrar que é possível haver mudanças e transformações. Como resultado, podem emergir aspectos utópicos projetados para a construção de uma nova realidade, de modo que só foram oportunizados mediante o arcabouço da velha sociedade.

Desse modo, existirá sempre conflito na construção da nova realidade, iniciada a partir das ideias de transformação, mudanças e a ruptura do existente em que caracteriza os principais elementos utópicos. No entanto, as principais ideias dos hábitos e valores embutidos no inconsciente dos indivíduos da velha sociedade permaneceram latentes e atuantes no que diz respeito à criação dos novos valores.

Os utopistas possuem um impasse que se revela por meio da negação com o existente. Dessa forma algumas batalhas ocorreram apenas para adaptação e fortalecimento das ideias que transcendem tanto a sociedade capitalista como a própria utopia. É improvável que se vivencie a utopia dependendo totalmente do ser no mundo. Uma vez que o mundo representa os elementos concretos e efetivos que estão em pleno funcionamento na sociedade refletindo no agir das pessoas. Para Mannheim (1976) há recorrente dificuldade na distinção teórica sobre utopias e ideologias. O impasse está apenas em determinar concretamente o que em cada caso seja ideológico e o que seja utópico.

Nesta direção, para estabelecer a diferença entre ideologia e utopia em sua premissa conceitual é preciso a efetivação necessária para partilhar os sentimentos e as motivações das lutas da realidade histórica. E que esses elementos conceituais nem sempre se encaixam na realidade da vida, por esses motivos que damos características aos elementos que estão fortemente presentes no N17, para então caracterizá-los e redefinir os conceitos, se apropriando do que mais convém e favorece.

Não obstante, a premissa da neutralidade científica e o fator científico parte da crítica aos fatores ideológicos se enquadram nesta mesma concepção das motivações ideológicas e utópicas. Fatos que também ocorrem com o elemento utopia, são criticados pelo "utopismo" pelo crítico realista. O objetivo da crítica é apenas caracterizar o outro como sonhador e irrealista; todavia o pressuposto das expressões são as posições políticas que cada uma delas possui. Contudo Mannheim (1976, p.220) descreve ainda que

Os representantes de uma ordem dada irão rotular de utópicas todas as concepções de existência que do seu ponto-de-vista jamais poderão, por princípio, se realizar. De acordo com esta utilização, a conotação contemporânea do termo "utópico" é predominantemente a de uma ideia em princípio irrealizável. 
É perceptível que para desqualificar as ideias utópicas, os indivíduos apostam em caracterizar essas ideias como irrealizáveis e desvinculadas do que é dito pelo sistema existente. Nesta direção, na esteira da história, os princípios ideológicos apontados pela esquerda, e que fizeram com que os jovens e adultos optassem pela ruptura do sistema, passassem a ser caracterizados como órfãos da geração que ousou sonhar e tentou lutar pelos seus sonhos. Por conseguinte, tornou-se difícil visualizar uma sociedade sem Estado, sem ordem, e que seja apenas gerida por indivíduos livres de regras. Pois, ainda em nosso subconsciente estão enraizados os valores e hábitos da sociedade que vivemos. Segundo Mannheim (1976, p.223),

Cada época permite surgir (em grupos sociais diversamente localizados) as ideias e valores em que se acham contidas, de forma condensada, as tendências não realizadas que representam as necessidades de tal época. Estes elementos intelectuais se transformam, então, no material explosivo dos limites da ordem existente. A ordem existente dá surgimento a utopias que, por sua vez, rompem com os laços da ordem existente, deixando-a livre para evoluir em direção à ordem e existência seguinte.

É no sentido da ordem existente dar surgimento a utopia que o rompimento dos laços da ordem existente se manifesta em diferentes épocas. Os indivíduos devem passar a acreditar que as mudanças podem ser possíveis. Nesse sentido, Mannheim ainda menciona que a mentalidade utópica é vista como idealismo, presente no senso comum e na "abstração" dos intelectuais. No entanto, a utopia não é apenas sonhos irrealizáveis, pois dá significado e legitima a ordem social existente. Pois o que coloca em xeque a sustentação do domínio capitalista será sempre considerado utópico e irreal. Porém, a utopia se manifesta como algo que indica o caminho possível e não algo que se realizável no momento presente.

As ideologias particulares quando se desprendem da ideologia total podem assumir características revolucionárias, passando a atuar como mecanismos ideacionais na construção de novas ordens sociais, capazes de se projetar como utopias. Deste modo, podemos dizer que ideologias têm um conteúdo utópico. Assim, a ideologia não é apenas método das classes dominantes para maquiar a realidade, mas pode desvendar aspectos da realidade que estavam encobertos.

Tanto a ideologia quanto a utopia estão necessariamente relacionadas a grupos sociais e só terá efeito se assim forem consideradas. Portanto, o indivíduo utópico que cria ideias precisa fazer com que elas circulem dentro do grupo, criando adeptos para corresponder no horizonte político por meio de ações que manifestem suas vontades dentro de um grupo. Ainda que muitas vezes as ideias revolucionárias não sejam acatadas em sua respectiva época, as ideias utópicas podem, em certa medida, ser incorporadas pelas futuras gerações, tendo em vista a construção de uma via para superar as contradições da ordem existente e, nesse sentido, continuam vivas.

Em suma, para Mannheim (1976) a utopia permanece necessária, pois seu desaparecimento ocasionaria um estado estático, condicionante o ser humano a incapacidade de se pensar e agir no mundo. Sem utopia o ser humano seria vulnerável, tornando-se refém de sua existência e, ausente de ideais, seria apenas um produto de motivações externas. Nesse sentido partimos da concepção de que a utopia, em seus componentes de transformação e de rompimento com a ordem existente, permanece necessária para que a sociedade possa ser construída de maneira plural e democrática.

PRACS: Revista Eletrônica de Humanidades do Curso de Ciências Sociais da UNIFAP https://periodicos.unifap.br/index.php/pracs ISSN 1984-4352 Macapá, v. 12, n. 2, p. 119-133, jul./dez. 2019 


\section{RESULTADOS OBTIDOS}

Os resultados obtidos podem ser classificados em cinco momentos que perpassam o N17 desde sua proposta inicial até o momento atual: 1) Racionalização e construção da mentalidade social; 2) Pensamento socialmente compartilhado; 3) Pensamento e ação; 4) Elementos totalizantes e aspectos parciais da mentalidade; 5) A construção de nova mentalidade diante dos valores do sistema. A análise destes cinco momentos em constante interação revela o pano de fundo da organização social e política do grupo, bem como permite indicar, por meio de uma abordagem psicossocial, anteriormente demonstrada na parte teórica desta pesquisa, as condições atuais de luta mediante os avanços realizados e os desafios que se apresentam cotidianamente para o fortalecimento das pretensões elaboradas na organização do coletivo.

O processo de racionalização e construção da mentalidade social, no contexto de criação do N17, pode ser constatado a partir do Estatuto Social (2017) que rege o grupo. A sociedade dos Agricultores Cooperados do Núcleo de Resistência Eldorado do Carajás (SOCIAEC) foi concebida como uma sociedade sem fins lucrativos, tendo em vista a base coletiva para desenvolver e fomentar a produção e os serviços com o objetivo de racionalizar os recursos financeiros e naturais da localidade para o bem-estar comum dos associados. Ainda de acordo com o Estatuto, a partir dos 16 anos os todos os membros passam para a condição de sócios efetivos da sociedade, gozando de seus direitos e deveres, bem como de suas vantagens e benefícios.

Esses aspectos assumem a objetividade na mentalidade social na medida em que o grupo se organizou, elaborando no âmbito comunicacional elementos outrora presentes no ideário subjetivo de seus membros. De acordo com observações e entrevistas/abertas realizadas in loco, tornou-se possível perceber que o grupo foi uma construção e, de modo concomitante, uma escolha dos membros, os quais só passaram a fazer parte do grupo por aceitação às propostas de cunho coletivo que fortaleciam os ideais da luta pela terra e pela sobrevivência compartilhada em conformidade com a construção de projetos utópicos que se colocavam constantemente em confronto com as ideologias competitivas e individualizantes do sistema econômico, social e político vigente.

$\mathrm{Na}$ conjuntura de formação de um grupo diferente dos demais que preza pelo coletivo em vez do individualismo, a estrutura de moradia foi pensada na mesma condição de coletivo. $\mathrm{O}$ grupo se organizou em agrovila de modo que as dezenove famílias fossem agrupadas em um lote que daria para construção da casa, que pudesse ter ainda um local pequeno destinado ao cultivo de pomares ou jardins. As casas foram alocadas uma ao lado da outra para que fosse mínimo o espaço destinado ao individualismo. De acordo com a Entrevistada I, "esse espaço é visto pelos moradores como sendo a única parte do grupo que detém da individualidade das famílias. O local é pequeno para que a condição de coletivo sempre seja maior que o individualismo. Tendo mais espaço no seu quintal as pessoas deixariam de plantar na área coletiva para plantar no seu quintal, deixando o intuito do grupo de lado.”

Diante deste processo de racionalização das condições de vida propiciadas pelo N17 aos seus membros, destaca-se como alicerce um pensamento socialmente compartilhado. É a partir do estilo de pensamento socialmente compartilhado e pelas experiências subjetivas do grupo que fizeram e fazem o N17 manter durante os últimos quinze anos organização coletiva, essa relação utópica em meio ao sistema totalizante que procura amiúde imprimir os impulsos e motivações provenientes da ordem capitalista. Logo, o pensamento socialmente compartilha- 
do de demarcações coletivas recebe pressões externas, mas, mesmo que as interações individualistas do meio perpassam o mecanismo implantado, observa-se que há um trabalho de formação da mentalidade social e política que é realizado desde a infância dos membros do grupo. É mediante o acompanhamento e compreensão das crianças que nasceram no grupo que se estabelece um processo de inserção, despertando a mentalidade de pertencimento ao grupo com suas características originais elaboradas por meio de sua orientação coletiva. Com base na observação realizada, identificaram-se elementos de linguagem compartilhada que corroboram na pretensão de constante fortalecimento do grupo como, por exemplo, "Vamos brincar com a nossa bola", "Vamos pinta com os nossos lápis". Tais comportamentos cotidianos transmitem a mentalidade do grupo aos membros mais jovens, inserindo-os gradativamente em um processo de organização coletiva e, com isso, imprimindo neles as determinações de corresponsabilidade pela manutenção do grupo. São elementos dissolvidos no cotidiano que mostram o que está sendo ensinado pelos adultos e que isso é absorvido pelos pequenos. As crianças do grupo a maioria são nascidas no grupo e, em grande medida, não vivenciaram da mesma maneira que os adultos o individualismo e a competição inerentes ao modelo social externo. As crianças são racionalmente conduzidas para o coletivo em seus diversos momentos: quando acompanham os pais na lida do dia do dia, no lazer, na mítica religiosa, nos afazeres da casa.

Destarte, os aspectos que organizam o cotidiano do N17 evidenciam a relação indissociável entre pensamento e ação. A forma de pensar do grupo, além de ser racionalmente projetada para a mentalidade coletiva e socialmente compartilhada, procura sua consolidação por meio das ações concretas dos indivíduos em relação ao coletivo. Porém, não há uma recusa da individualidade, mas o agir com os outros faz o indivíduo pensar como os outros e a agir também. A opinião e a discordância têm espaço dentro do respeito por um grupo plural e mesmo se manifestando contrário aos pontos de vista dos outros o indivíduo mantém por princípio fundamental a base ideacional do grupo ao qual pertence, diferindo-se dos outros e lutando pelo desenvolvimento das potencialidades em meio ao coletivo.

Assim, pensar e agir são correlatos, mesmo que compreendidos separadamente. Como pode ser constatado na fala de um dos entrevistados do N17: "As crianças que tem nos ensinado muito, temos prestado muita atenção no comportamento das crianças." (informação verbal $)^{3} \mathrm{O}$ principal componente destacado por quem participou da construção da mentalidade social e política do grupo e procura imprimir nas crianças os valores coletivos é o comportamento individualista. Conforme é notável na fala do mesmo membro entrevista, o grupo tem a convicção de o individualismo é um comportamento deve e pode ser mudado na mentalidade social: "Nós adultos tivemos um período fora do grupo e quase metade da vida fora daqui. A gente viveu muito tempo no individualismo fora e a gente ainda tem um pouco do individualismo aqui que é a casa da gente que dai cada um faz do jeito que quer [...]" (informação verbal) ${ }^{4}$ Para o entrevistado III, ainda sobre o comportamento individualista o modo como o indivíduo se relaciona com dinheiro torna-se central: “...o dinheiro que pega investe se quiser e tal e ainda tem isso aqui dentro do grupo, por estamos num sistema capitalista onde o sistema ai fora diz o que." (informação verbal) ${ }^{5}$ Outro componente destacado

3, 4, 6 6 II, ENTREVISTADO. Entrevista. [fev. 2016]. Entrevistador Silvana Piva. Entrevista concedida a dissertação de mestrado: Por outro Desenvolvimento: uma abordagem da mentalidade socioeconômica do Núcleo de Resistência Eldorado dos Carajás - UEMS. Ponta Porã/MS 2018. 
pelo entrevistado é a competição colocada como via essencial de crescimento: "que eu tenho que te usar pra ser escada para mim crescer... então todo dia a gente vive esse conflito." (informação verbal) 6

O individualismo e a competição não foram totalmente removidos do N17. A luta cotidiana é para reforçar a mentalidade do grupo, desenvolvendo as formas coletivas de convívio com gradações de pensamento e ação. Com base nas formas de agir socialmente no mundo, Mannheim (1972, p.32) afirma a existência de nuances dentro do grupo: "Estas pessoas, reunidas em grupos, ou bem se empenham, de acordo com o caráter e a posição dos grupos a que pertencem, em transformar o mundo da natureza e da sociedade a sua volta, ou, então, tentam mantê-lo em uma dada situação". No caso do N17, os indivíduos se empenham em transformar o mundo e a sociedade a sua volta por meio da ininterrupta necessidade de implantar nas ações cotidianas a mentalidade social sustentada na coletividade, resistindo às pressões da ideologia e da lógica de funcionamento do sistema capitalista. Essa resistência se dá principalmente diante da imposição da perspectiva do individualismo. A concepção política que fomenta os ideais do grupo é a resistência ao que advém de fora do grupo em diferentes esferas da organização social. Por se tratar de um grupo aberto e em relação constante com os processos externos, o que permeia o vínculo entre pensamento e ação é a necessidade de resistir e se reafirmar ao longo do tempo ao longo de 15 anos. Resistir na forma de organização coletiva proposta pelo e para o grupo para viver esse modelo de organização. Porém, é inviável desvincular-se do sistema externo em sua totalidade, conforme comentou em uma em uma de nossas visitas uma mulher que participou da organização inicial do N17: "Nós dependemos infelizmente do sistema a nossa proposta de organização quer mostrar que é possível sim viver de forma mais igualitária e coletiva e por esse motivo é que vamos resistindo." (informação verbal) ${ }^{4}$

O conflito que emerge com frequência no grupo está ligado a tensão causada pela aproximação entre a mentalidade construída com base no coletivo e os elementos sistêmicos da semântica capitalista que se revelam nas motivações individualistas e competitivas. Apesar de existir uma proposta totalizante em defesa do coletivo, nas particularidades da vida cotidiana, os indivíduos são impelidos ao desejo de seguir outros rumos que caracterizam a procura pelo benefício particular. Essa dimensão que condiciona o surgimento do conflito no N17 é o que podemos diagnosticar como relação cambiante entre elementos totalizantes e aspectos parciais da mentalidade social. Na aproximação entre as categorias de ideologia e utopia, o N17 apresenta comportamento de ruptura das amarras existentes, forçando intencionalmente o descolamento da ideologia imposta pela modernidade capitalista. Junto a isso, o grupo se lança em direção aos conteúdos utópicos na medida em que optou por um modo não convencional de organização e formação interna de seu grupo, tentando quebrar e modificar certas imposições, principalmente se tratando de igualdade e solidariedade perante o grupo. Esses elementos transcendem a ordem estabelecida na totalidade da dinâmica social, mas revela em seu interior ataques externos da ordem que se pretende recusar. Tais ataques se consolidam por meio de práticas individualistas e processos altamente competitivos provenientes da ordem externa vigente.

${ }^{4}$ II, ENTREVISTADO. Entrevista. [fev. 2016]. Entrevistador Silvana Piva. Entrevista concedida a dissertação de mestrado: Por outro Desenvolvimento: uma abordagem da mentalidade socioeconômica do Núcleo de Resistência Eldorado dos Carajás - UEMS. Ponta Porã/MS 2018. 
Este conflito pode ser concebido em termos dos intercâmbios existentes entre dois modos da ideologia se manifestar e se propagar dentro do grupo. Em sua conotação particular ou parcial a ideologia se revela nas visões de mundo que estão tacitamente colocadas nos indivíduos e causam interferência na realidade histórico-social do coletivo. No N17 a ideologia parcial ou particular está embutida em cada pessoa que faz parte daquele grupo, nas particularidades, valores, princípios e crenças trazidas de suas vivências de mundo em estágio anterior a construção do grupo. Já a ideologia total se orienta e busca a legitimidade pelo pensamento desiderativo que orientou a criação do grupo com base nas pretensões de coletividade, desenrolando-se nas experiências vividas durante esses 15 anos na perspectiva de continuar lutado em prol de se manter na terra, fomentando uma metodologia de vida diferenciada pautada no bem-estar da coletividade.

A possibilidade de refundar a ideologia total, isto é, os elementos totalizantes da vida em sociedade, surgiu na criação do N17. De maneira semelhante, as ideologias parciais provenientes das perspectivas externas e incorporadas no grupo se colocam como obstáculos que, em grande medida, visam desintegrar o projeto de organização social e política lançado pelos membros do comitê de organização e também pelos representantes dos movimentos sociais. Na fala de uma das organizadoras do N17 é possível resumir as pretensões assumidas inicialmente: "Decidindo que o grupo teria um modelo contrário de organização com moldes totalmente coletivos divergindo totalmente com os demais grupos sociais ali alocados." (informação verbal) ${ }^{5}$. De acordo com Mannheim (1976), conflitos deste tipo tendem a necessariamente ocorrer em meio à dinâmica inerente às tentativas de rompimento com a ideologia preponderante. Trata-se, pois, do modo que os novos indivíduos criados com as revoluções e as transformações não nasceram prontos e sim necessitavam da velha sociedade e dos velhos valores para então poder clamar por novos modelos de sociedade em que pudesse ser levada em consideração a classe menos favorecida.

A partir dessa conjuntura os elementos díspares das visões de mundo são irremovíveis do N17, pois o grupo necessita de recursos para a sua sobrevivência que advém do sistema, mesmo que estruturado em moldes utópicos que refere se ao seu modo de organização interna. Tanto pela sua forma de inserção do todo na hora do plantio ou pela divisão de tarefas, os diferentes componentes do passado e do presentem se mesclam e assume papel preponderante dentro do conflito ininterrupto com o foco na maior eficiência. Em outras palavras, o passado e o presente, a interioridade e a exterioridade, são dimensões que interagem dentro de uma mesma realidade que precisa priorizar a geração de renda para o grupo.

Diante deste cenário híbrido, é possível identificar no N17 a construção de nova mentalidade diante dos valores do sistema. Por um lado, é inviável afirmar que o N17 seja um estágio social utópico, pois, o mesmo comporta elementos histórico-sociais da ideologia da sociedade moderna e capitalista. Há no grupo de modo irremovível hábitos e valores em sua organização inconsciente que são desdobramentos das ideologias vivenciadas na sociedade total e que foram experimentados antes da criação intencional e racional do grupo. Entretanto, a proposta de organizar um grupo de novo tipo, com uma mentalidade coletiva, oportunizou um pensamento socialmente compartilhado que visualiza o rompimento com as determinações elevadas do individualismo e da competição exacerbada. Com a efetivação desse novo forma-

\footnotetext{
${ }^{5}$ I, ENTREVISTADO. Entrevista. [fev. 2016]. Entrevistador Silvana Piva. Entrevista concedida a dissertação de mestrado: Por outro Desenvolvimento: uma abordagem da mentalidade socioeconômica do Núcleo de Resistência Eldorado dos Carajás - UEMS. Ponta Porã/MS 2018
}

PRACS: Revista Eletrônica de Humanidades do Curso de Ciências Sociais da UNIFAP https://periodicos.unifap.br/index.php/pracs ISSN 1984-4352 Macapá, v. 12, n. 2, p. 119-133, jul./dez. 2019 
to de organização pautada no coletivo, os membros que compõem o N17 manifestam sua ideologia particular e em conjunto, a partir do convívio um com os outros durante esses quinze anos de caminhada, colocam em prática as ações que visam recriar e reinventar a sua própria história. Tais indivíduos procuram a afirmação de si como sujeitos históricos que pretendem forjar uma ideologia total, conflitando entre si suas visões particulares.

Por certo, os ideais utópicos se fazem presente principalmente quando o grupo reitera sua forma de se organizar. Junto a isso, emerge de modo objetivo em meio ao grupo o sentimento de que seja viável para as gerações futuras a formação da sensação socialmente orientada de pertencimento ao coletivo por meio das vivências e experiências do grupo. Os indivíduos do N17 tratam o "espaço, território e lugar" não de forma particionada, mas sim como lugar comum de todos os que estão envolvidos e no processo de criação e recriação da vida.

Diante desta formação social híbrida e cambiante, o N17 se destaca na elaboração concreta do espaço coletivo em confronto com a elevação da mentalidade individualista. Apesar de não ser um produto concreto da mentalidade desiderativa que esteve na base de sua criação, os traços utópicos que fazem frente ao sistema podem ser percebidos em vários momentos da vida social do grupo. É a partir do pensamento em ação que a utopia encontra caminhos de realização. É quando os ideais de organização social são evidenciados na alteridade dos membros do grupo, retomando o propósito maior da resistência e afirmando constantemente o coletivo sobre o individual, aspectos da mentalidade utópica são despertados.

Por fim, em meio a configuração social do N17, a educação assume um espaço preponderante tanto para a resistência quanto para a reorganização dos ideais que mantêm o grupo coeso. É no liame do sonho abraçado que se dá a resistência a luta do grupo coletivo em manter nesses moldes até o presente momento em consonância com o que buscaram transmitir para as novas gerações. Conforme destaca uma das fundadoras no grupo, "As nossas crianças aqui vivem isso daqui. As crianças brincando juntas eles não têm esse contato lá fora." (informação verbal) 9 . Para a Entrevistada I, de modo concreto a educação tem um papel central:

“[..] Tem uma criança do grupo que chego na escola no prézinho para estudar e no primeiro dia de aula a mãe foi lá compro lápis de cor, compro caderno tudo bonitinho. Ai ela chegou na escola e chamou a atenção da professora. Foi a professora que conto. "eu não vou cansa de conta isso nunca porque é ai que gente consegue perceber que o método que a gente está educando nossas crianças é percebido fora e é diferente. $\mathrm{E}$ as vezes nos olhando aqui dentro não imagina que é percebido fora. Ai ele chego ele simplesmente pego a caixa de lápis de cor abriu a caixa de lápis de cor jogo encima da mesa e falo assim "VAMO GENTE PINTA ESSE É OS NOSSOS LAPIS". Os detalhezinhos que fazem a gente dá conta que jamais ele ia briga com um coleguinha porque o colega pego o lápis dele para pinta. Porque as nossas crianças aqui já compreendem que isso daqui é nosso não é MEU é nosso". (informação verbal) 10

A continuidade na mentalidade social do grupo se revela no contentamento em viver de modo coletivo: "Então a gente nessas horas a gente se sente realizada pelo fato de que você está educando teus filhos de uma forma diferente da sociedade que está aí fora. Por mais que temos que conviver com essa sociedade. Mais que eles estão vendo de forma diferente." (informação verbal)11 $\mathrm{O}$ desejo de continuidade se expressa na mentalidade das novas gerações, conforme identifica-se neste relato: “A minha filha mais velha esses dias falo pra mim a 
gente ali em casa do nada conversando tem só 12 anos e vem com essa conversa "Mãe escuta me fala uma coisa essas casa tudo desse jeito aqui quando eu casa onde vai ser minha casa?" (informação verbal)12 Logo, a perspectiva do coletivo incutida nas novas gerações reforça nos fundadores do grupo os seus ideais, conforme destaca a entrevistada I do N17: "Você entende daí a gente começa a se dar conta que a gente erro, e a gente jamais penso isso. A gente se dá conta que eles têm amor por isso daqui." Além disso, afirma ela: "Eles não pensaram em casa e ir embora daqui eles vão fica aqui porque eu quero casa e trazer alguém pra morar aqui." (informação verbal)13 Em suma, a vida cotidiana permeada pela alteridade consolida a forma de organização do N17: “Então são as coisas do dia a dia que a gente vai avaliando que a gente não está errando na nossa forma de organização.” (informação verbal) ${ }^{14}$

\section{CONCLUSÕES}

Em consonância com a pesquisa realizada, percebemos que a mentalidade social do N17 se revela, em um primeiro momento, como resistência à medida que espaço de organização socioeconômica é construído e transformado continuamente por seus atores, colocando-se estes na condição de sujeitos de sua existência. Junto a isso, cada indivíduo busca o seu lugar no grupo mesmo que se submetendo e corroborando com o avanço ou regresso do processo que participou da construção, mas mantém de maneira cambiante sua consciência em prol da coletividade.

Diante disso, o N17 emerge como um grupo não finalizado, sendo constantemente constituído pelas relações compartilhadas pelos indivíduos que se colocam como construtores do meio social. A dinâmica inerente e constitutiva do grupo levou a pesquisa a compreender os aspectos mutatis mutandis em diferentes direções. A partir do diálogo entre teoria e empiria percebemos que as ideologias atuantes dentro do sistema colaboram para a formação do N17 a partir da manifestação das ideias em ação. Por outro lado, as utopias, enquanto perspectiva de superação do sistema, emergem atreladas às projeções utópicas que circunscrevem a mentalidade social na forma de crença e cobrança entre os indivíduos. O sonho passa a ser abraçado pelos membros do grupo, moldando e ressignificando as utopias que se pretendem realizáveis. Em contrapartida, novas ideologias advindas do sistema são constantemente infiltradas no interior e na construção da mentalidade social do N17. Tanto os aspectos ideológicos quanto utópicos são reatualizados constantemente. E, neste processo ininterrupto entre a crença no coletivo e o perigo iminente do individualismo podemos considerar que emerge no N17 uma forma híbrida de organização social entre ideologia e utopia.

Fomos norteados inicialmente pela apreensão da conjuntura de organização e formação histórica do N17. Temos, por conseguinte a compreensão mediada pelo diálogo entre a teoria e a empiria de que o processo de organização promoveu e promove a consciência de que por mais que forças do sistema capitalista adentrem a formação do grupo, o mesmo consegue por seus arranjos, sonhos e perspectivas de vida voltada para o coletivo criar fissuras importantes no sistema.

\section{REFERÊNCIAS}

BITTAR, Marisa. Mato Grosso do Sul a construção de um estado: regionalismo e divi-

PRACS: Revista Eletrônica de Humanidades do Curso de Ciências Sociais da UNIFAP https://periodicos.unifap.br/index.php/pracs ISSN 1984-4352 Macapá, v. 12, n. 2, p. 119-133, jul./dez. 2019 
sionismo no sul de Mato Grosso. Volume I. Campo Grande, MS: Ed. UFMS, 2009.

DENCKER, Ada de Freitas Maneti. Métodos e técnicas de pesquisa em turismo. São Paulo: Futura, 1998.

ESTATUTO SOCIAL. Sociedade dos Agricultores Cooperados do Núcleo de Resistência Eldorado do Carajás - SOCIAEC. Ponta Porã/MS. 2017.

FLICK. W. Introdução á pesquisa qualitativa. Tradução Joice Elias Costa. 3ed. Porto Alegre: Artmed. 2009.

HAGUETTE. T. M. F. Metodologias qualitativas na Sociologia. $5^{a}$ edição. Petrópolis: Vozes, 1997.

INSTITUTO NACIONAL DE COLONIZAÇÃO E REFORMA AGRÁRIA - INCRA.

Reforma Agrária, 2015. Disponível em: <http://www.incra.gov.br/reformaagraria $>$. Acessado em 20/04/2016.

I, ENTREVISTADO. II, ENTREVISTADO. Entrevista aos membros do Núcleo de Resistência Eldorado dos Carajás. [fev. 2016]. Arquivo sonoro. Entrevistador Silvana Piva. Entrevista concedida a dissertação de mestrado: Por outro Desenvolvimento: uma abordagem da mentalidade socioeconômica do Núcleo de Resistência Eldorado dos Carajás - UEMS. Ponta Porã/MS 2018.

MAY, Tim. Pesquisa social. Questões, métodos e processos. 2001. Porto Alegre, Artemed.

MANNHEIM, Karl. Ideologia e Utopia. Rio de Janeiro: Zahar Editores, 1972. MANNHEIM, Karl. Ideologia e Utopia. Rio de Janeiro: Zahar Editores, 1976.

TERRA, Ademir. Reforma agrária por conveniência e/ou por pressão? Assentamento Itamarati em Ponta Porã - MS: "o pivô da questão". Presidente Prudente/SP: UNESP, 2009.

PLANO DE DESENVOLVIMENTO DO ASSENTAMENTO ITAMATATI - PLA.

Instituto de desenvolvimento Agrário, Assistência Técnica e Extensão Rural de MS. IDATERRA. Campo Grande 2002. 